\title{
CONGESTION AND URBAN LOCATION
}

\author{
LESTER B. LAVE, Carnegie-Mellon University
}

Lach of the functional systems within a cily is highly interactive. The demand for transportation depends on the locations of residential areals, work areas, shopping arcas, and recreation areas. The location and type of housing demanded depends on the quatity and cost of avatiahle Iransportation. Other important components in the analysis include the size of cily, demand for freight transportation, amount of congestion, and means for regulating congestion. Mast attempts to iselate a single system for analysis, such as the demand for urban passenger transportation, have been less than complete stlcessses because these other systems cannot be held constant; the various systems are simply 100 intertependent for "other things held constant" to be a very useful technique of analysis.

In an carlier paper, I made a moxlest heginning in an altempt to explore some of these interdependencies [8]. One model of the interaction between residential localion and transportation mode was explored along with moxdels of congestion and congestion toils and a model of urban decentralization. This paper is the product of ellorts to generalize some of these models and to include congestion in each aspect of transportation and city size. It should be stressed that even though the models become more eomplicated, they are pale images of reality: every eflurt has been made to keep them suffecienlly simple that analytical results can be derived.

The hatsic model is more than one hundred years old $[22,4]$ and seems 6 have been rediscovered by it number of investigators, including Mohring [I2] and this author. Perhaps the most complete development of this type of model is done by Alonso [1] who generalises the problem to nonlinear functions and explecilly considers the utility function of a landowner in deriving locational pallerens. In a recent paper. Beckmann [2] derives the residential location pattern from an explicit maximization of the consumer's utility function fatsuming a Pareto distribution for income and a logaritimic utility function).

\section{A SIMPLE VON THUNEN-ELLET MODEL}

Consider a city whose factories and stores are located in the city eenter. All fand (outside the cily center) is allocated to housing. Initially, it is assumed that

Any views expressed in this paper are these of lic author. who is consultant to the Rand Forporation and should not be interpreted as rellecting the views of Rand or the otticial opinion or policy of any of its governmental or private rescarch sponsots.

This researd, was supported, in parl, hy the [ trited States 1)epartment of Transportation, federal Railread Administration, Onice of High Speed Ground Transpottation. A related version of this anaterial was prosluced for the Northeast (ooridor Transporlation Project as R $\wedge$ ND Memerandum RM-587.4 DOT. Tramsportation. City Size aml Consestion Tolls. 
the demand for land is lotally inelastic (for simplicity, all lots are of identicat size) as is the demand for travel. The cost of travel (to work or to shop) is defined to include both the cash outlay and the time spent; it is a function of the distance to be traveled. 'Houghout this paper, it is assumed that the city center is a point (it takes up no spatee itself) and that travel is direct. "as the crow flies," A plausible form for the cost of trated is shown in cyuation (1),

$$
\begin{aligned}
T_{i} \quad & r(a-b r) \\
= & r^{*}(a: b r)
\end{aligned}
$$

where $T_{i}$ is the dollar cost per day of the annual trips between the eity center and a lot of unit area which is $r$ feet from the city. Travel cost is a linear function of distance with a multiplicative factor, the citys population $P$, 10 aceount for congestion.' When the size of residential loss is constant, population is proportional to the areal of the city, where the boundary is $r_{0}$ from the city center. Since all shopping and work are in the city center, it is assumed that all trips are between home and the city eenter." lor such a city, llacest of travel will be minimized in al circular configuration with the city center located at the geometric enter of the circle.

It is further assumed that the only reason for living close to the city center is that travel cost is lower than if one lives farther out. Residents can be expected to bid for "in lownt" property in order to save commuling costs. The rent of any piece of land will relleet the sivings in travel cost. Thus. lor all land which is occupied, the sum of the daily rent and the travel cost will be constant (assuming that residents make the same number of round trips per day). "Marginal land" is land far enough from the city center so that its rent is cero. Rent falls to zero at the point where the commuting cost is so high that, even with positive rent, land nearer the city center hals lower total cost (rent plus travel). L.et $r_{11}$ be the distance from the city center of marginal land (that which carries a gero rent). ${ }^{3}$ The rent will be zero and the ravel cost

$$
T_{i b} \cdots r_{0}^{\prime \prime}\left(a \mid b r_{0}\right) .
$$

Any lot $r_{i}$ (which is $r_{\text {f }}$ feet from the city enter) will have a travel cost

1 Ihis formulation has congestion increase very rapidly as the city grows. It might be defended as a reasonable approximation lo what would happen if other kind of adjustment, e.g. olher transportation modes and some decentralization, were not allowed to oceur. If the reader finds the assumption extrenke, the model is sufficiently simple that it is casy to substitute an alternative assumption.

: An equivalent set of assumptions is that all travel which is not between the city center and homc oxcurs in a manner which is inclependent of the Iocation of one's abode, i.c. local shopping centers are spread unifomly thenghout the city, and one's friends live in close proximity lo home. Although this set of assumptions is more general than that in text, it is not quite equivalent to that in the text if congention is greater near the city center.

"T The distance of matginal land from the city center will vary as the number of persons demanding land varies. lligher demand means higher rent, which increases the distance from the center one can go before trivel cost exceeds tent at the eenter. 


$$
\begin{aligned}
T_{1}= & r_{i}\left(a+b r_{i}\right) \\
\mathrm{R}_{i} & =T_{0}-T_{i} \\
& \cdots: r_{0} b\left(r_{\mathrm{b}}-r_{i}\right)
\end{aligned}
$$

and a rent $\quad \mathbf{R}_{i}=T_{v}-T_{i}$

the cost of otcupying a lot at $r_{i}$ is the sum of rent and travel cost as shown in equation (2).

$$
\begin{aligned}
T_{i}+R_{1} & -r_{0}^{2}\left(a \mid b r_{i}\right) \mid \cdot r_{0}^{2} b\left(r_{0}-r_{i}\right) \\
& =r_{0}^{2}\left(a+b r_{0}\right) .
\end{aligned}
$$

What is the supply curve for residential land? The cost of occupying a lot. dependis on the travel cost from the marginal land. The larger the eity, the greater will be the rent of any lot a fixed distance from the center. If marginal land is $r_{i}$ feet from the eity center, the total cost of occupying a square foot of land (rent plus travel cost) will be $r_{i}^{2}\left(a+b r_{0}\right)$. The total area of the city will be $A \quad \pi r_{n}^{2}$. The supply curve for residential land is given in equation (3).

$$
\text { L. . } T \mid R=\left\{a\left|b\left(\frac{1}{\pi}\right)^{1 / !}\right| \frac{1}{\pi}\right.
$$

where the total cost of occupying a square foot of land (the "standard" size lot) is

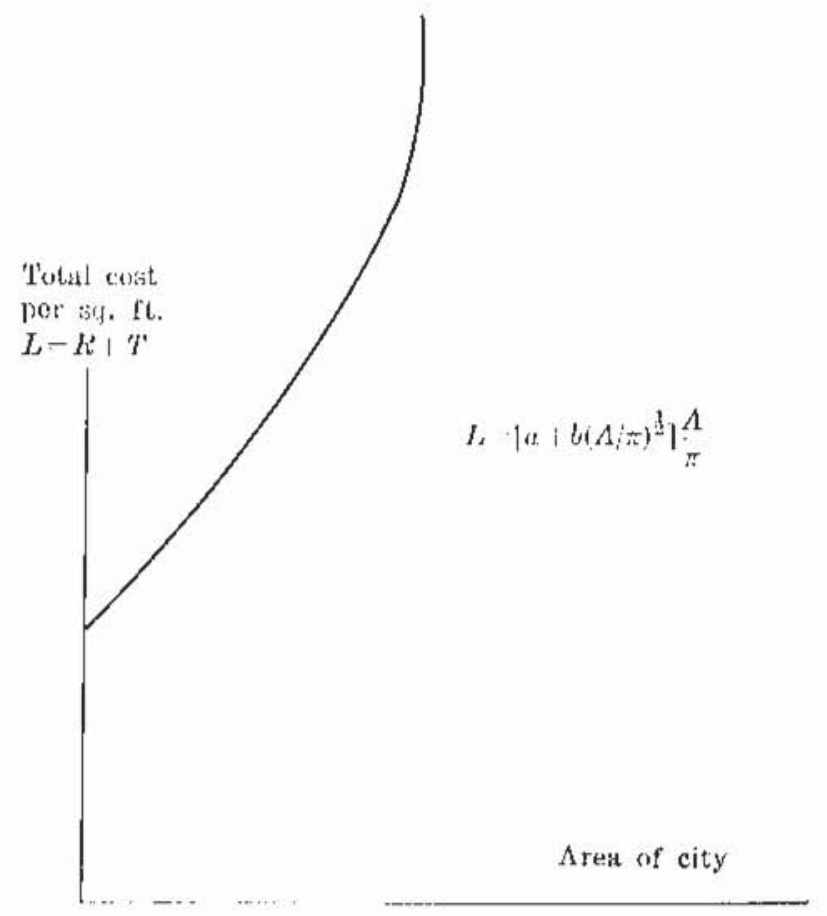

Frgurt 1. Tuf Surpty Curve for Residence in that Ciry 
a function of the area of the city, as shown in Figure I. (This formulation holds not only for a round city but for any slape which is the sum of equal radius pieshaped wedges.)

\section{A Measure of Benoflt In the Model}

The total cost of residence in the city is casily calculated in this moticl. takch

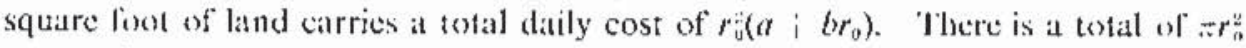
square fect of land in the city, and so the total cost of occupying land is given in equation (4).

$$
L_{0}=r_{0}^{2}\left(a+b r_{0}\right) \pi r_{i 1}^{*} .
$$

Note that the total travel esst is

$$
\left.r \quad \int_{11}^{r_{0}} r_{i} 2 \pi r d r \quad \int_{0}^{r_{0}} r_{u}(a \mid b r) 2 \pi r d r=\left(a \mid \begin{array}{ll}
2 \\
3
\end{array}\right) r_{0}\right) \pi r_{m}^{2}
$$

and the total expenditure on rent is

$$
R \quad \int_{0}^{r_{11}} k_{i} 2 \pi r d r \quad \int_{0}^{r_{11}} b r_{0}\left(r_{11} \quad r\right) 2 \pi r d r-\frac{b \pi r_{0}^{h}}{3} .
$$

If transportation were frec and instantaneous, all rents would be zero in this merlel. Rents exist only because transportation is costly (in terms of both moncy and time). If a way eould be lound to improve transportation, its cost would decline and all residents would benefit." Rents might also fall, but this drop cannot be added to the decrease in transporlation sost. Rent changes are purely a transfer: changes in travel cost are changes in the use of scarce resources. In this model, ignoring distributional considerations, the correct measure of benclit from at transportation improvement is the drop (both in terms of time and money) in transportation cost.

There are two sorts of changes that might improve transpoitation. The fiust is a fall i!? $a$, the lixesl sost of travel. This "cost af getting isatly w travel" must be borne by everyone, and everyone would benefit equally from a reduction in a. The effect of a change in $a$ is shown in the lirst part of equation (5).

$$
\begin{aligned}
& \begin{array}{ll}
\lambda T & \pi r_{11}^{4}
\end{array} \\
& \frac{\partial T}{\partial h}-\pi r_{0}^{5} / 3 .
\end{aligned}
$$

In this case, there will be no change in rents. The second change that would bo a benetit involves a fall in $b$, the cost per foot traveled. Such a fall might eome from expanding highways or synchronizing traffic lights. Those living farthest from the city center would obtain the greatest reduction in transport cost from a fall in $b$, while those living in the center would obtain a relatively small immediate

\footnotetext{
4 Excent absentec landlords, whose rental income would fall.
} 
gain. Ilowever, since ecntral property now has a smaller advantage vis-a-vis Iransportation, its rent must fall relative to marginal land. 'This will continue until total cost (travel cost plus rent) is again the same throughout the city. This clange in the structure of rents due to competition will cause a transfer from landlords to tenatnts so that all tenants eventually henelit equally while landlords lose a unitorm portion of their rents.

If the assumptions of this model were relexed slighlly so that the demand for land had some positive price clasticity, a futher consequence would occur. One might expect people to secupy more land than previously, since its price had falien as a result of the fall in $b$. As a conseguence, the town would expand and transportation expenditures would rise, though possibly not back to the former level. This increase in land accupied indicates the existence of a further benefit. This result is important for the measurement of benefit. When the demand for land increases, the fall in transportation cost fealculated on the existing yuantity of transport services) is no longer a precise measure of the benefit of a technological change.

\section{Immigration}

What is the ellect of migration into or out of the cily? Immigrants will recuire their own lots and so the area of the city must expand. Suppose the migrants locate around the periphery, between $r_{0}$ and $r_{1}$. Their travel cost will be higher than that at $r_{0}$. Consecuently, they will be willing to bid some positive rent for the previously marginal land at $r_{0}$. If the distance of marginal land from the city center jncreases from $r_{4}$ to $r_{b},-\pi\left(r_{i}^{*} \quad r_{\tilde{v}}^{*}\right)$ additional square liet of fand will be added to the city. If the immigrants occupy $n$ square feet of land, $r_{1} \ldots\left(n / \pi \mid \cdot r_{0}^{2}\right)^{t / 2}$.

Before the migrants arrived, at $r_{\|}$the rent was zero and the tolal travel cost was $\left(a \mid(2 / 3) b r_{0}\right) \pi r_{0}^{4}$. With migration, both rent and travel costs are higher. Rent (per square fout) now rises by $h\left(r_{3}^{*}-r_{i 1}^{3}\right) \mid b r_{i}\left(r_{1}^{*} r_{0}^{*}\right)$, and travel cost per day per person increases by $\left(r_{1}^{2} \quad r_{0}^{2}\right)\left(a-b r_{i}\right)$. The cost per day lo everyone of the immigration is shown in equations (6) (8).

$$
\begin{aligned}
& \text { Rent increase } \quad 3^{\pi} \pi\left(r_{1}^{\bar{j}} \quad r_{0}^{5}\right) \text {. } \\
& \text { Travel cost increase } \quad a \pi\left(r_{1}^{1} \quad r_{11}^{\prime}\right): \frac{2}{3} b \pi\left(r_{i}^{i} \quad r_{0}^{i+}\right) \text {. } \\
& \text { Jotal inctease } \quad a \pi\left(r_{1}^{3} \quad r_{b}^{b}\right) ; \cdot b \pi\left(r_{1}^{3} \quad r_{1}^{n}\right) \text {. }
\end{aligned}
$$

The immigrants pay only part of these increases; current residents must pay the rest. The external cost of immigration is the increased cost which is not borne by the immigrant; these costs are shown in equations (9)-(11). These equations are obtained by multiplying the reut and travel cost increases per scyuare foot by the number of scpuare feet occupied by the original residents. 
Rent externality

$$
\int_{0}^{r_{11}}\left[h\left(r_{1}^{3}-r_{i 1}^{3}\right)+b r\left(r_{11}^{2}-r_{i}^{2}\right)\right] 2 \pi r d r \cdots \frac{b}{3} \pi r_{i 1}^{11}\left(3 r_{1}^{2}-2 r_{11} r_{i}^{3}-r_{0}^{7}\right) .
$$

Travel cost externality

$$
\int_{i 1}^{r_{0}}\left(r_{i}^{2}-r_{i 1}^{2}\right)(a+b r) 2 \pi r d r \quad{ }_{3} \pi r_{i k}^{2}\left(r_{1}^{2}-r_{11}^{2}\right)\left(3 a+2 b r_{0}\right) .
$$

Rent plus travel externality

$$
r_{u}^{2}:\left[a\left(r_{1}^{2}-r_{0}^{2}\right) \cdot \mid b\left(r_{1}^{3}-r_{1}^{3}\right)\right] .
$$

'To optimize the allocation of resources, technological externalities must be taken into account in deciding to immigrate or emigrate. However, before rushing of Io place a tax on immigration and a subsidy on emigration, the costs in equations (9) and (10) must be examined carefulty. Who receives the increased rent slown in equation (9)? This rent is a transfer payment from renters to owners; changes in this sort of rent are a pecumiary externatity and need not be considered in optimizing resource allocation (increased rent does not mean that any additional scare ressures are heing used). The increast in travel cost does represent it twehnological externality, that is, additional resources are recpuired to make the same trip after the city has expanded since the migrants increase congestion for all travelert. A larger, more pepulous cily means that more cars wili be on the road at any given

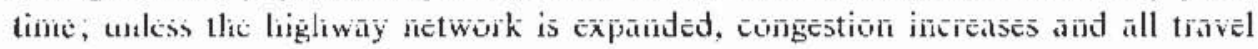
becomes more expensive.

In this model, there is a technological externality only bectuse of the increase in congestion. If there were no congestion, there would be no travel cost externality, and the increase in rent would be a pecuniary externality; no taxes or subsidies would have to be imposed to optimize the allocation of resources. Thus, congestion leads to a qualitative change in this simple model. The existence of congestion means that immigration will lead to a misallocation of resources unless congestion tolls and subsidies are imposed."

Thus, a per day lax equal to the amount shown in equation (10) ought to be imposed on immigrants. ${ }^{7}$ Similarly, any current resident should be offered a bribe

The fact that the increased rent is a pecuniary externality can best be secen by supposing that cach person owns his house and land. When a mighant enters, the value of every nerson's house and lot rises, but this increase is of two concern. If someone residing at $r_{i}$ were to decide to capitalize on the increased value of his house, he would sell it to the immigrant and nove to the no-rent periphery. which is now at $r_{1}$. He would find thal the increase in the value of his property duc to immigration is just large enough to oflset the increase in trivel eosts date to the fact that he must now travel from $r_{1}$ instead of $r_{i}$.

6 Ihe model can be alkered so that the immigration leads 10 a technological externality without congestion; sec the formulation in [8].

7 The reason for taxing migration shnuld be clearly understood. The tax is not levied because expanding a city results in a higher cost to all residents. Rather, the tax is required because a migrant decs not face the nuarginal cost of migration in deciding to enter or leave. If I tecide to 
of this amount to leave the city. (Note that all beneficial effects of greater city size are neglected, such as possible economics of agglomeration.)

fiveryone should face a per day lax of the magnitude given in equation (10). This amount is the penalty he is imposing on all other people by living in the city and thereby adding to highway congestion. If everyone were to pay this tax, the city would collect a substantial amount of revenue. Such a tax might provide sufficient revenue to meet the cily's needs. Indeed, the tax could be great enough so that part of it would have to be returned to the taxpayers ats at subsidy. On equity grounds, one could ask that the subsidy be in proportion to the amount paid. However, one would have to be careful that the purpese of the tax was not destroyed by the subsidy.

Lven a cursory took at urban transportation problems makes it evident that there is a substantial cost to people concentrating in an area fo form at city. Since the trend to concentrate in urbat areas is continuing. one might infer that there are some oflsetling cconomies of agglomeration." Thus, when an immigramt moves in, current residents experience some of the benefits from the economies of agglomeration, and the immigranl experiences the rest. At the same lime, current residents experience some of the costs in the form of both pecuniary and technelogical externaltics while the immigrant also experiences some of the costs. A major reason for the disarray in our cities is the fact that important technological externatities are not aceounted for. It would only be by the ptrest chance that external costs and benefits of immigration were remotely equal. But even if they were identical, urban resourees would be allocated badly. To athicve an eflicient allocation of resources, taxes and subsidies for technological externalities must be properly levied. The tax in this model is a lax on congestion designed to internalize the increase in travel cost that one residen imposes on all ofler travelets. Relaxing the assumptions of the model a bit, the effect of the tax is to encourage people to shate rides and travel at off-neatk limes. A subsidy to encourage immigration and internalize economies of agglomeration is a subsidy for participation in the city; it las little to do with how many people ride in a car or when people travel. To achieve efficient resource allocation, both tax and subsidy nust be levied separateJy so as to encourage both immigration and less congestion on the highways.

\section{The Demand for Property}

So far, it has been alssumed that all lots are the same size. Thus, $R$ is the rent for a "standard" lot and $T$ is the Iransportation cost. If each individual is to be

enter this city, current residents will have to pay an anksun whose sum is equal to equation (l0): if a current resident decided to teave, all other residents would receive a total benefil equal to equation (10). In order to have each individual face the true marginal cost of migration, immigrants numt pay a tax and emigeants receive a subsidy equal to equation (10).

* Another possibility is that, from a social standpoint, it is not optimal to have large cities continue to grow. Perhaps, if all technological externalities were accounted for, large cities would cease to grow. 
allowed to cherese the sire of his kot, the tratvel cost function, $T_{2}, \cdots r_{i l}\left(a ; b r_{i}\right)$ will have 10 be modilied. The radius of the city $r_{11}$ is in the function as a surrogate for the number of cars on the highwaty. The reakler should not be misled into believing that congestion is a function of city size (number of ears on the highway and highway capacity held constant). ('ity size is relevant in that the larger the city, cetcris parihus, the longer one must bear each level of congestion. However, this fact does not result in a technological extcrmality. As shown by Strotz [19]. the fact that one must bear a given amount of congestion for a knger time when los sizes increase is completely captured in the rental price of land; no additional tax or subsidy is required to optimize the allocation of resources.

As shown previmsly [8], allowing the size of lots to vary wilt result in central lols being smaller than average and lots on the periphery larger than average. At the same time, the structure of land rents will change se that the rental price (per square foot) is higher for central land and lower for peripleral land than that calculated in the model sketebed here. Thus, in comparison with a eity where all lets are of ickntical size, a city whose lots are free 6 vary will have lot sizes increase as one moves away from the city center and will have a rent gratient that falls more rapidly as one moves away from the city center.

\section{A TWO-MODE MODEL}

So far, transportation has been assumed to cost the same amount for everyone. An interesting variation oceurs if this cost varies from one individual 10 another, ats when transportation is assumed to be time-consuning, and the value of time is not the same for all residents. Let $w_{\text {r }}$ be the value of time to the "rich" and $w_{n}$ be the value of time to the "poor." Suppose travel time is a lincar function of distance, $t_{i} \quad a+f_{i}$; initially. there is no eongestion in the model. The

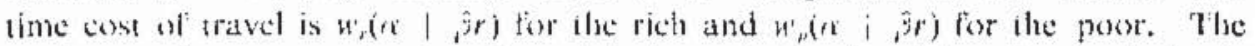

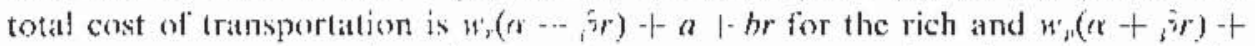
$a+b r$ for the poor. Since it costs the rich more to travel a given distance the value of their time is greater), land near the center has a relatively high value to them. Whatever land at $r_{i}$ is worth to the rieh, a lot at $r_{i} \quad 1$ is worth $w_{r_{i}} \beta+b$ less for the rich and $w_{r i} 8 \mid b$ iess for the poor; these expressions determine the rent gradients of the rich and poor, respectively.

Since travel is relatively more costly for the rich, they will bid away land near the city center antil they have salisfied their demand." The poor will live around them in a ring. the width of which is determined by their demand. To determine the rent sirueture, note that land at $r_{0}$ las a zero rent and a (ravel cost of $w_{p}\left(\alpha<i, j r_{v}\right)+$ $a \cdot \mid b r_{v}$. The sum of rent and travel cost for the poor must always equat this

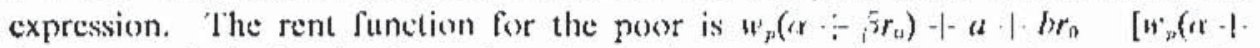
$\left.\left.\hat{\beta} r_{i}\right)|a| b r_{t}\right]$; that is, the savings in taavel cost over that incurred at $r_{0}$. At the

"Demand for lots is assumed to he price inclastic in this model, with the rich demanding a fotal areat $a_{r}$ and the poor a total arca $a_{p}$. 


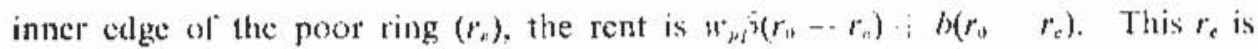
marginal land for the rich; however, its rent is not rero to them. In order to obtain the inner circke, they must bid il away from the poor. At $r$, they must bid as much as the poor, and their rent gradient must be steeper than $w_{13}^{\beta}+b$. Knowing that rent at $r_{0}$ is $w_{p} \beta\left(r_{11}-r_{1}\right) ! b\left(r_{0}-r_{n}\right)$ and that the travel cost is $w_{r}\left(e r+\beta_{0} \beta r_{e}\right)|\cdot a|$ $b r_{r}$, it is apparent that the tolal cost of oceupying a lot for the rich is $w_{p} \hat{\beta}\left(r_{0}-r_{n}\right)+$ $b\left(r_{0}-r_{c}\right) \div W_{r}\left(r \mid f_{r} r_{c}\right)|a| b r_{c}$. Thus, the cost of any lot for the rich will be

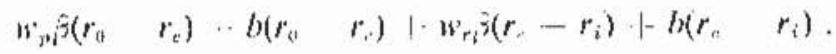

This argument is illustraled in Figure 2.

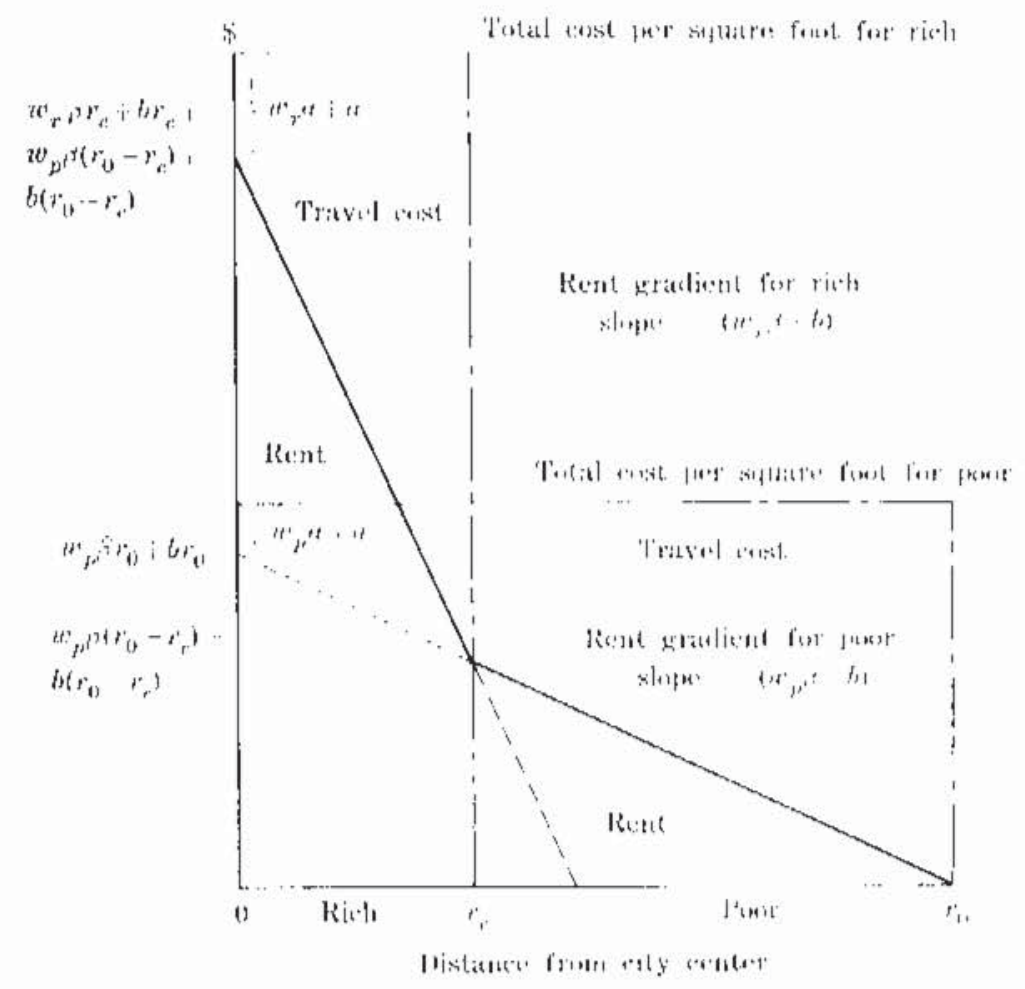

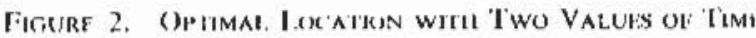

The botizontal axis meisures the distance of a lot from the city eenter; the vertical axis is in dollars. For any $r_{i}$, the vertical distance to the rent gradient measures the rent for a lot $r_{i}$ from the city center (note that the rent at $r_{b \text { i }}$ is zero). The total cost of occupying a 100 is measured by the height of a rectangle. Thus. the travel cost at $r_{i}$ is the vertical distance from the rent gradient to the top of the 
rectangle. At $r_{e}$, the rent of rich and poor are equal and so the two rent gradients intersect. Note finally that the travel cost at $r_{i}$ () equals $w_{r} r r+u$.

Suppose now that there are two modes but only onc valuation of time. One mode is fast and costly: the other is cheap but time consuming. The "costs" of the two modes are the sum of time and cash costs. For the fast mode, the cossts are $w\left(r_{f}, \beta, r\right)$ and $a_{f} \mid b_{f} r$; for the slow mode, the costs are $w\left(r_{x} \mid, j, r\right)$ and $a_{x}+$ $b, r$. One mode might always dominate or the slow mode might be cheaper to use for a short distance, although it is cheaper to use the fast mode for greater distances.

As an illustration, suppose that the fast mode costs $42+3 r$, and the slow mode costs 2 | 13r. As shown in Figure 3, the slow mode will be faken for distances

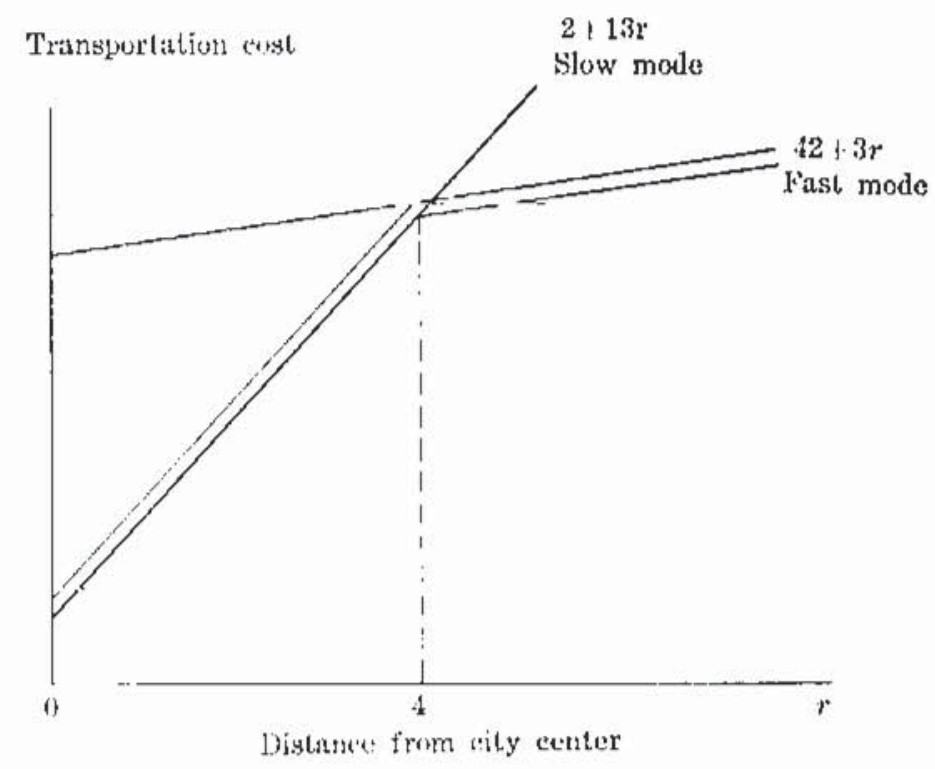

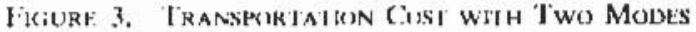

up to 4, and beyond that the fast mode will be taken. The rent of a lot at $r_{i}$ is (assuming $r_{n} \therefore 4$ )

$$
\begin{array}{r}
3\left(r_{0}-r_{i}\right) \quad r_{0}=4 \\
3\left(r_{0}-4\right) \mid 13\left(4-r_{i}\right) \quad r_{0} \leftrightharpoons 4 .
\end{array}
$$

The wotal cost of occupying a square foot of residential land is $42+3 r_{11}$ throughout the city, depending only on the cost of the mode that dominates at the edge $r_{0}$.

Finally, one might suppose the existence of two modes and two valuations of time. The costs of the two modes will diller for rich and poor. The cost of the fast mode "auto" is $w_{r}\left(\alpha_{f} \mid \cdot, 3, r\right)+a_{f}+b_{f} r$ for the rich and $w_{p}\left(r_{f}+z_{f} r\right)+a_{f}+f$ $b_{f} r$ for the poor. The cost of the slow mode "walking" is $w_{r}\left(\alpha_{*}, \beta_{*} r\right) ; a_{0} \mid b_{x} r$ for the rich and $w_{n}\left(\alpha_{*}+\hat{\gamma}_{k} r\right)+a_{*} \mid b_{w} r$ for the poor. It is not very interesting if 
one node is cheaper for both rich and pror. Suppose $w_{c}>w_{\mu} ; w w_{x} \mid a_{x}<$ $w r, \mid a_{f}$ for both rich and poor; and $w_{j} \hat{\beta}_{j} r\left|b_{f} r<w_{j} \beta_{e} r\right| b_{e} r$ for both rich and perer. In sther words, travel time is worth more to the rich than to the poor, the lixed cost of travel (the cost of getting reaty (o) travel) is higher for the fatst mode than for the slow mode, and the marginal cost of travel (the cost of going an extra foor) is more cxpensive on the slow mode than on the fast one. Under these conditions, as is shown in ligure 4 , there will be 1 wo crossover points: at $r_{a}$, the rich will change from walking 10 auto, and, at $r_{b}$, the peror will change.

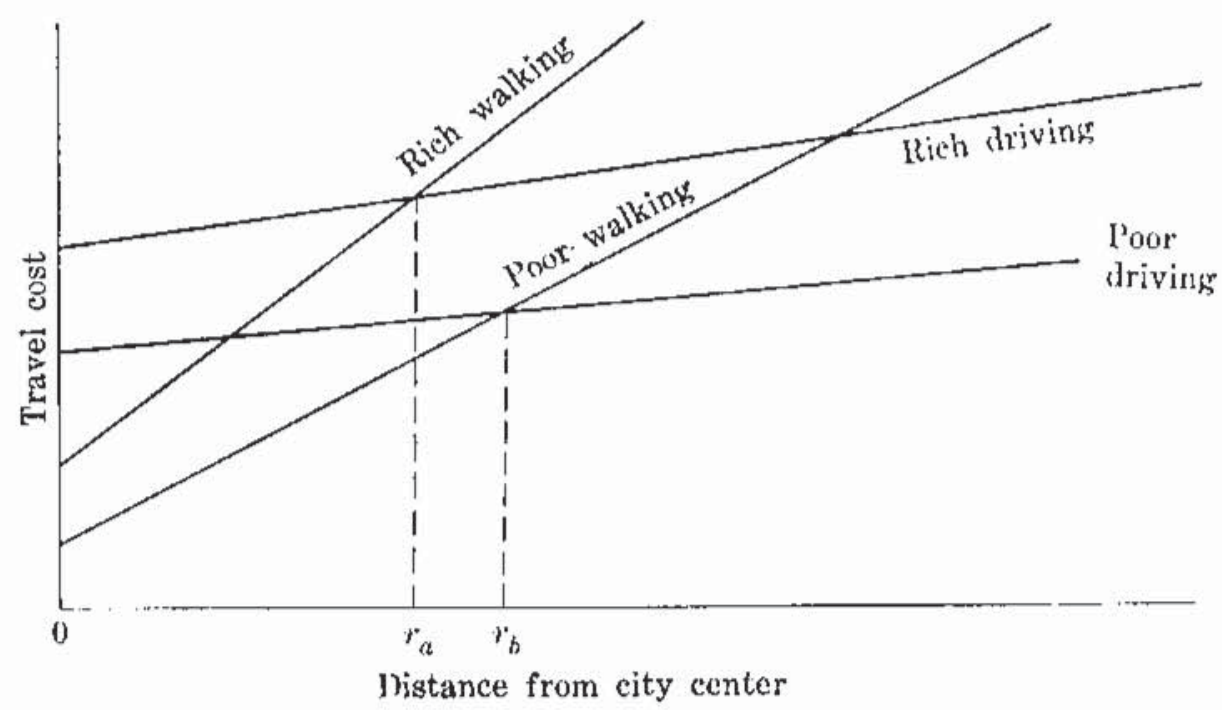

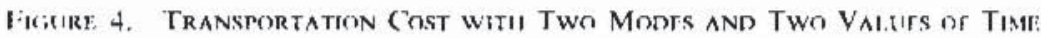

This case is best analyzed via a particular illusiration. I.et the cost of the fast mode be w(10|2r) $32 \mid r$, and the cost of the slow mode is $w(1+11 r)+1$ $+2 r$. The fast mode has a relatively high lixed cost (32: 10w as compared 10 $\left.1-w^{\prime}\right)$, since it is both time consuming and expensive to warm up an automobile and take it out of the garage. However, the fast mode has a low variable eost $(r$ 1. $2 r w$ as compared to $2 r \mid 11 r w)$, since it is both faster and cheaper per mile than walking. Thus, for short distances, one is willing to walk, since the cost of getting ready to walk is small: for longer dislances, the high setup cost of driving is worthwhile since it is more than counterbalanced by the low variable cost of driving.

Now suppose that the wage rate of the rich is $w, \quad 2$, and the wage rate of the poor is $w_{p}=1$. Then the cost of the fast mode is $52 \mid 5 r$ to the rich and $42+$ $3 r$ to the poor; the cost of the slow mode is $3 \mid 24 r$ to the rich and $2 ; 13 r$ to the poor. It is now easy to calculate the points where rich and poor elect to switch modes. For distances greater than $21 / 1 \mathrm{~m}$, the rich will always take the fast mode; 
for shorter dislances, they will always lake the slow mode. For distances greater than 4, the poor will always take the fast mode; for shorter distances, they will always take the slow mode.

Given the demand for property by rich and poor, all lecations, rents, and transportation costs are determined. (Remember that each individual wisles to minimize the total cost of occupying a lot, that is, the sum of rent and 1ravel costs.) There are four possible lecettional patterns lor cities of our model; these are shown in ligure 5. Pattern $\mathbf{I}$ corresponds to the locational patterns shown in Figure 2, since both rich and poor walk; the rich live in the inner circle, and the poor live in
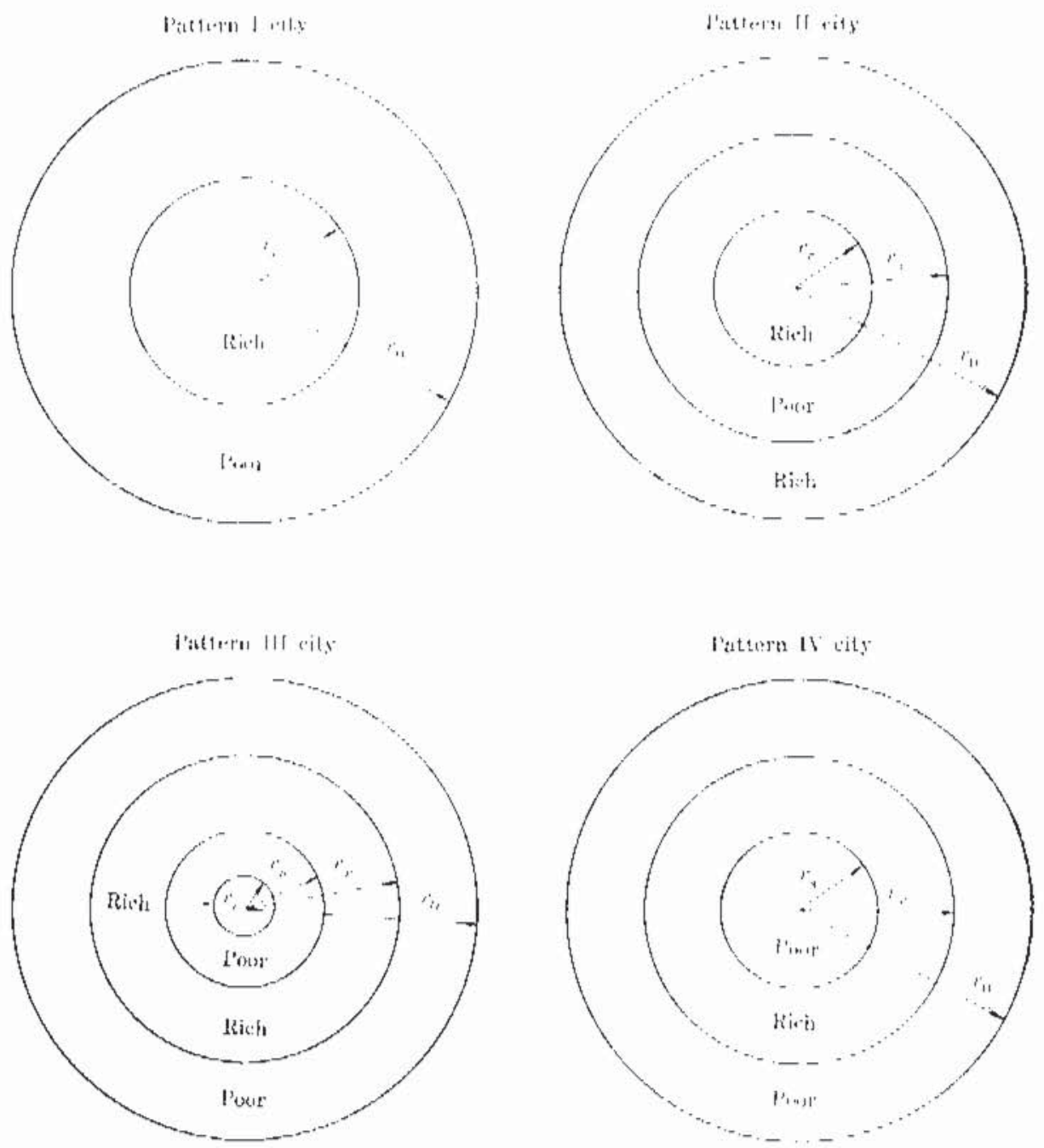

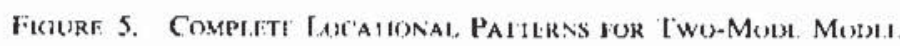


the ring surrounding them. As the demand for land of rich and poor increases, a Pattern I city will become a Pattern II city, and some of the rich will begin (o) live in a ring surrounding the ring of the poor. Note that the rich who live in the outer ring tse the fast mode (auts) while everyone else walks. Those rich using the fast mode have a comparative advantage in travel and so live loward the eclge of the city. As demand of rich and poor grows, the city will atsume the shape of a Pattern 111 city. As shown in Figure 5, all of the ricls now live in an outer ring, and the poor have taken over the whole of the central circle. If the city continues lo grow, additional poor will locate in a ring beyond the rich. The poor who lecate in the outermost ring use the fast mode; since the value of the time is lower than that of the rich. they locate beyond the rich. This situation is represented by Pattern IV.

To make these notions more precise, let us call the boundary of the imet circle $r . .$, the boundary of the ring between pour and rich $r_{\text {n }}$ (the "suburbs"), and the boundary between "suburbs" and "rural" area, $r$. Then the rent functions for : Patton I city are given in equation (12).

$$
\begin{aligned}
& 13(r, \quad r) \quad r \quad \because r \cdot r \\
& \left.13\left(r_{11}-r\right) 24(r) \quad r\right) 0 \because r r_{c} .
\end{aligned}
$$

To he precise, for this pattern, $r_{i}$ must be less than or equal to $21 / 11$. the peint at which the rich begin to use the fast mode, and, in addition, the areal demanded by the poor must be smail enough so that it is not to the advantage of any rich to move to $r_{0}$ and drive. This means that the total con of excupying a lot at $r-0$ must be less than or equal to the total cost of occupying space at $r$, for a rich man. Thus, $13\left(r_{11} r_{c}\right)\left|24 r_{0}\right| 3 \quad 52 \mid 5 r_{0}$. This implies that it $r_{0 .} 21 / 1$, , there are no poor in the city $\left(r_{1}, r_{n}\right)$ : if $r_{1,} \quad 1 \% / 1, r_{1,} \quad 4$ and the poor exeupy at area of $13.61 \pi$ : if $r_{s} \quad 0, r_{11} \quad 61 / \mu$ and the poor occupy an area of $37.5 \%$. In order lor a city to assume Patiern $I, r_{\mathrm{c}}$ and $r_{0}$ must satisfy the inequality $11 r_{e}+8 r_{0}<49$.

For a Pattern Il city, the rent functions are shown in equation (13).

$$
\begin{aligned}
& 5\left(r_{\mathrm{n}} \quad r\right) \quad r_{\mathrm{a}} \because r \Leftrightarrow r_{\mathrm{n}} \\
& 5\left(r_{11} r_{A}\right): 13\left(r_{3} \quad r\right) \quad r_{c} \because r r_{*} \\
& 5\left(r_{\mathrm{ii}} r_{s}\right) \mid 13\left(r_{s} \ldots r_{r}\right)+24\left(r_{r}-r\right) \quad 0 \because r \cdots r_{r} \text {. }
\end{aligned}
$$

Nole that the total cost of a lot (to the rich) must be the same in the suburbs as it is in the inner circle. Thus, $52-5 r_{\mathrm{n}}-3: 24 r_{e}+13\left(r_{\mathrm{e}}-r_{\mathrm{o}}\right) \cdot 1 \cdot 5\left(r_{0}-r_{\mathrm{s}}\right)$ or $49-11 r_{n}: 8 r_{n}$. Thus, when $r_{c}-0, r_{n}=61 / 8$; when $r_{c}-211 / 4, r_{8} \cdots 21 / 1 \%$ In the former case, the poor oceupy an area of $37.5 \pi$, and there are no rich. In the litter case, there are no poor, and the rich oceupy an area of $6.65 \pi$. In order for a city to assume Pattern II, $r_{r}$ and $r_{*}$ must satisly the equation $49-11 r_{*}+8 r_{*}$,

When the demand for land of the poor grows enough, the cily fits Pattern III; the rich occupy the central area, the poor surround them out to the suburbs, which 
are oceupied by the rich, and beyond the suburbs are the rural poor. The rent functions are shown in equation (14).

$$
\begin{aligned}
& 3\left(r_{11}-r\right) \quad r_{r}<r<r_{0} \\
& 3\left(r_{11}-r_{r}\right)+5\left(r_{r}-r\right) \quad r_{0} r_{r} \\
& 3\left(r_{u}-r_{r}\right)+5\left(r_{r}-r_{n}\right)+13\left(r_{s}-r\right) \quad r_{n} \leqslant r<r_{s} \\
& 3\left(r_{n}-r_{r}\right)+5\left(r_{0}-r_{n}\right)+13\left(r_{1}-r_{n}\right)+24\left(r_{0}-r\right) 0<r \leqslant r_{0} .
\end{aligned}
$$

The structure of a Pattern III city is derived by noting that the cost of residenee for the rich must be the same whether they live in suburbs or eentral eity, and the cost of residene for the pror must he the same whether they live in the eity or surrounding rural area. These constraints give rise to the simultaneous equations shown in equation (15).

$$
\begin{aligned}
& 49-11 r_{r} \mid 8 r_{.} \\
& 408 r_{r}+2 r_{r} .
\end{aligned}
$$

One example of a Pattern III city is $r_{1,}-2^{3 / 1}, r_{,}, 3, r_{,}, 8$, and $r_{11}-n$ where $n$ can be any number greater than 8 .

$A$ lurther increase in demand will change a Pattern III city into a Pattern IV city by forcing all of the rich out of the inner circle into the suburbs. The rent functions are shown in equation (16).

$$
\begin{aligned}
3\left(r_{n}-r\right) & r_{r} \leq r<r_{0} \\
3\left(r_{0}-r_{n}\right)+5\left(r_{r}-r\right) & r_{n} \leq r \leq r_{r} \\
3\left(r_{n}-r_{r}\right)+5\left(r_{r}-r_{n}\right)+13\left(r_{n}-r\right) & 0 \leq r \leq r_{n} .
\end{aligned}
$$

The requirement that the cost of residence for the poor be the same in the rural area as in the suburbs means that $40=8 r_{t}+2 r_{r}$. An example of a Pattern IV city is $r_{s} \cdots 2.5, r_{r} \cdots 10, r_{a}-n$ where $n$ is any number greater than 10 ).

Pattern I might be identified as a small city, Pattern II as a moderale sized cily, and Patterns III and IV as large cities. These identifications are not precise in that they depend on the relative demands of rich and poor for land, as made precise in the conditions above (for example, $r_{n}<(49 / 19)$ must be a Pattern I city, and $(49 / 19) \leq r_{0} \leq(49 / 8)$ may be a Pattern I city). These identilications also depend on the time and cost characteristics of the two modes remaining unchanged as city size increases. This assumption seems doubtful in that congestion might impede the fast mode more than the slow one.

Without belaboring this model excessively, one might add a congestion factor to see its effect on rents and urban location. If both fast and slow modes become equally congested, the underlying structure is held constant, and all of the previous results will be reproduced in substance, even though the exact numbers will change 
slightly. The more interesting calse oceurs when one mode, presumably the fast one, is subject to congestion while the stow mode is congestion free. Suppose that the lime and cost of travel on the fast mode depends on the number of people in the city; that is, all commuters, not just those using the fast mode, contribute to fast mode congestion. For example, if the slow mode were walking or bicycling, the number of pedestrians or cyclists would slow the average speed of atutomobiles. Assuming that lot size is constant, the travel cost of the fast mode would hecome $(52+5 r) r_{0}^{2} / 100$ for the rich and $(42 \mid \cdot 3 r) r_{6}^{2} / 100$ for the poor; the cost of the slow mode is unchanged. The point where one switches from slow to fast mode now becomes a function of population $\left(r_{n}\right)$ as shown in Table 1.

IABLE 1

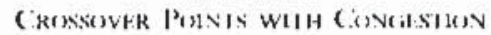

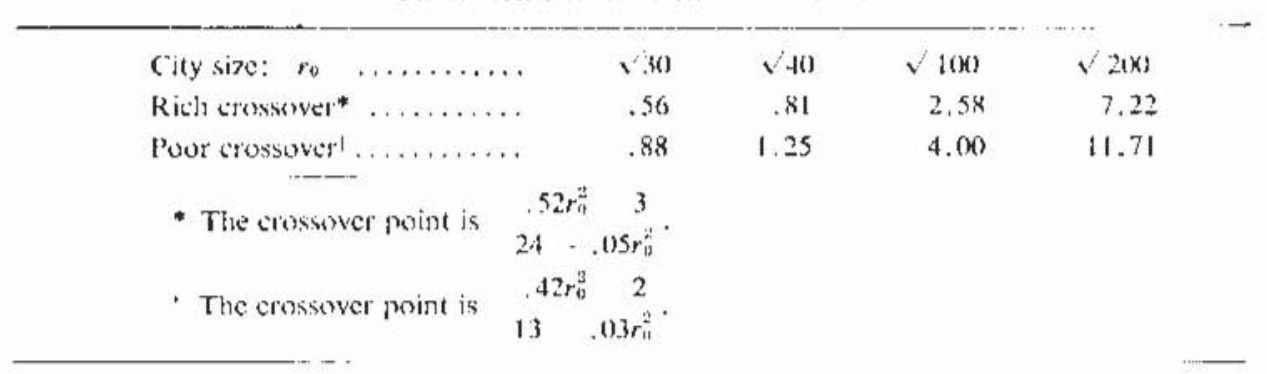

Congestion does not affect the fact that there ate four ponsible city location patterns. The rent functions for Patterns I IV are shown, respectively, in cepuations (17) (20). Thus, congestion does not complicate the formulation in the sense of changing location patterns or the basic rent structure.

$$
\begin{aligned}
& 13\left(r_{11}-r\right) \quad r_{c} r r r_{0} \\
& 13\left(r_{1}-r_{\mathrm{o}}\right)+24\left(r_{\mathrm{o}}-r\right) \quad 0 \therefore r \leq r_{\mathrm{e}} \text {. } \\
& \frac{r_{n}^{*}}{20}\left(r_{0} \quad r\right) \quad r_{0} \therefore r<r_{v} \\
& r_{00}^{2}\left(r_{11}-r_{n}\right)+13\left(r_{0}-r\right) \quad r_{n} r r_{\Delta}
\end{aligned}
$$

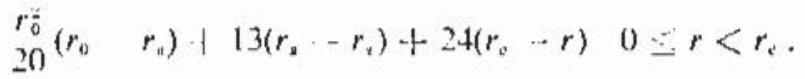

$$
\begin{aligned}
& .03 r_{\| \prime \prime}\left(r_{\| 1}-r\right) \quad r_{r} r \leqslant r_{0} \\
& .03 r_{0}\left(r_{u} \quad r_{r}\right) \mid .05\left(r_{r} \quad r\right) \quad r_{*} \because r r r_{r} \\
& .03 r_{0}\left(r_{\mathrm{n}} \cdot r_{r}\right)+.05\left(r_{r}-r_{*}\right) \cdot 13\left(r_{4}-r\right) \quad r_{0}-r=r_{*} \\
& .03 r_{s}^{2}\left(r_{n}-r_{r}\right) \div .05\left(r_{r}-r_{s}\right)+13\left(r_{s}-r_{n}\right)+24\left(r_{s}-r\right) 0 \leq r \leq r_{e} \text {. }
\end{aligned}
$$




$$
\begin{aligned}
& .03 r_{11}^{2}\left(r_{\mathrm{il}} \cdot r\right) \quad r_{r}, r \because r_{\mathrm{u}}
\end{aligned}
$$

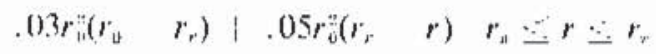

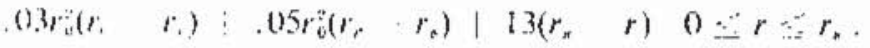

This simple model is suggestive of one aspect of the urban lecation decision. Of course, the model is lerribly simple, and reasoning trom th to the world is tenuous. However, one might nose that cities have grown considerably in the last two decacles. In Hoese two decades, many cities have swilched from Pattern I to Pattern II; that is, they have developed suburbs for the middle class. It is probable that these high income people were non fleeing lle central city, but rather were taking advantage of the antomobile as at better way of commuting. If one desired at stup the "light to the subutbs" of high income residents, one should stop spending moncy to improve atuto Iransportation and rather spend the money on improving public transportation. One wotald be foolish to predict that transportation time

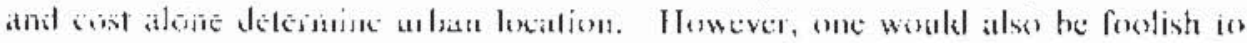
deny that dhey have an elfeet. The better is commuting by atuto, beth in time and cost, the more people can be expected to move ont to the suburbs. Not that it pays the rich to move oul lirsl (as city sire expands). On the nother hand the hotter is the public transpontation system (both in terms of time and cost), the more poor peeple will keave the cily center. Therefore, it would seem unreasonabie fior cities to be concerned about the growing percentage of urban poor in the city and the fatling tax revenues caused by high income cilizens moving to line suburbs and, at the same time. spend Jarge sums to improve auto transportation lo the suburbs, ${ }^{10}$

\section{SUMMARY AND CONCLUSION}

This paper has outlined an explemation of the interactions between he mature of transporlation, rent patterns, and loeation patterns. Within these simple models. changes have been explored (such at that resulting from congestion or that stemming from an improvenent und transportation lechnologyl allong with the implications for secial wellare. The primaty advantage of such a simple model is the caxe with which alternative assumptions ean be exploreo. Its simplicily allows antlytical solutions to be derived. which means that a benefit-cost analysis of improving turban transportation is easily accomplisicd within the modet. The model is sulficiently complicaled that complex patterns of location and rents cunerge, when two modes and Iwo values of time are introduced. High and low income residents cluster into patterns stgggestive of these prevailing in comlentporaty cilies.

Congestion, which slows the pace of urban transportation and increases its

1" Anulke bil of casuat empiricism is that New York seems to be a Pallern III city and Ios Angeles at latlern IV city. Good public transpenation combines with atitombile congestion in New Yojh lais tended to keep some rich in the sity center. In Los Angeles, a car is reqardid as a necessity: thus there is nes advantage to living in the city eenter (fir the rich). The poor are forced to put up with poor public transportation or wallh. 
wost is ubiquitcous. When congestion is incorporated ints these models, it hats the eflew of complicatting locational patterns and associating a technological externality with immigration. To optimise sity sies, it is necessary to place a congestion tax on city residence and to wlier a subsidy to current residents il they leave the cily.

Some analytical morlels of congestion have been explored elsewhere." Their implicallion is that traffic congestion leads 10 a marked technological externality. If the externality were to be incorporated in user's decisions properly via a congestion toll. the foll woukd he quite substantial and could be expected to have at marked eflect on transportation decisions. The tolls are sufficiently high that one would expect a signilican increase in the number of eccupants per car and in the proportion of oft-peak travel.

This formulation suggests a rather simple model of decentrulization. A benelit recurs in the model when transporlation costs are reduced. For example, if a city could be divided so that there are Iwo city centers, tratnsportation expenditures would fall by 30 per cent. Dividing a city into four city centers would leatd 10 a 50 per cent reduction in transportation expendilures.

To determine optimal city size, the economies of agylomeration must be adided to oflset the redaced travet cost of decentralization. One simple way of doing so is to suppose that there are $N$ commoditics (or commodity groups), each of which is produced under substantial cconomies of scale. In dividing a city into several pieces, it is assumed that each eity center will prokltace alt of any particular group of commodities. 'Thus, with two city centers. each produces half of the commoxlity groups and ships hatl of its prodiction to the other city center. Thus, the ollsetling economy of agglomeration is the cost of shipping commodities to the wher city center(s).

As shoun in [8], as soon as it becomes profitable to decentralize the city at all, the optimal number of cily centers is indefinitely large. The only factor limiting the number of centers is the assumption that, while each commodily group is proaluced under economics of scale, the production of any two commodity groups is independent. Thus, ane cily center would be engaged in the production of coaliron-sted while ansther was engaged in producing research-education. The conclusions of this model seem to accord quite well with reality in that as soon as transportation lechnology madc it profitable to decentralize a large city, the result has been a multitude of individual slopping-work centers rather than a gradual move to first two then three city centers.

\section{REFERENCES}

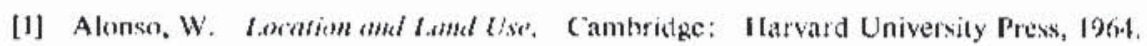

[2] Bechmann, M. "On the Distribution of Urban Renl and Residential Density," Jotmal of Economic Theory, 1, 1969, pp. 60-67.

"Sec |8, sect. II]], [6]. [7]. [9]. [14], [15, 16], [17, 18], [19], [20, 21], and [23, 24]. 
[3] Brighan, E. "Ihe Detcrninan!s of Residential Iand Valuc," Lamd Ecomomiss, VXIJ, 191,5, np. 325-334.

[4] Fillet, C. An Exsey on the Laws of Troth. New York: Augustus Kclley, 1893.

[5] Hatris, R.. G. Tolley, and C. Harrel, "The Residence Site Closice," Revicw of Litonemics ant statistics, I., 1968, pr. 241-247.

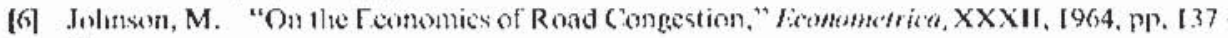
150.

17] Kraft, G, and M. Wohl. "New [Directions for Jassenger Denland Analysis and lorecasting," Tramsprostution Ressturst, II, 1968.

[8] Lave, L. Transportation, (ity Sizc, and (ingessitin $\gamma_{0} / h$, The RANI) Corporation, RM$587.4-1)(3) 1,19(19)$

[9] I ave, I. and J. DeSalvo. "Congestion, Tolls, and the Itconomic Capacity of a Waterway." Jonomal of Political ticonomy, I.XXVI, 196\$.

[10] Mills, L:. "An Aggregative Modst of Resuurce Allusation in a Mctropolitan Arcal," American Foromernic Rovicw. 1.VII. np. 197210.

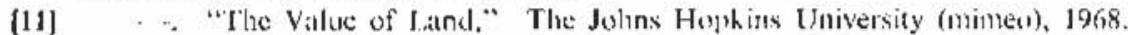

[12] Mohring, 11. "I and Values and the Measurement of Highwaty Benetits," Jotomil of Polit-

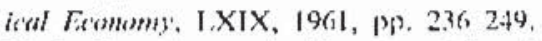

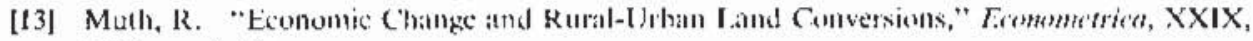
IMt, pN. 1-23.

[14] Roth, G. "An Fesmomic Approach to Traftic Congestion," Fown Ifammin Kevie"t, XXXVI, 1965, pp. 4961.

[15] Sharp, C: "Congestion and Welfare: An Lxamination of the Case for a Congestion Tax," Ficmomic Joturmal, I.XXVI, 1966, pP. 816 817.

[16] - "Congestion and Weltire Reconsidered," Journat of Tramsont Frommiss and Policy, 11, 196\%: Pp. 119.125.

[17] Smecd, R. "Iraflic Studics and Urban Congestion," Jtumat of Tramsport Ecommmits and Policy, II, 1\%,8, , ор. 3,3-70.

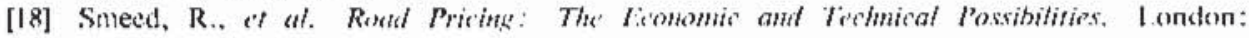
H. M. Stationery Ollice, No. $55411,1 \%(14$.

[19] Strotz, R. "IJban Transportation Parables," in The Public Leonomy of Urban Commanitios, J. Margullis, el. Washington, D.C.: Resources for the future, 1965, np. 127-169.

[20] Vicksey. W. "Optimization of Traffic and Ficilitios," fontnal of Tramsport Eaconemics and Policy. I. 1967. P1. 12, -1,36.

[21] . "Congestion Charges and Wellare," Jommal of Transport ticonomics and Policy, II, 1968, pp. 107-118.

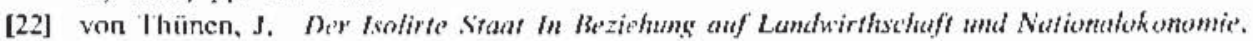
Berlin: Wiegandt, 1836.

[23] Walters, A. "The Theory and Measurenent of Private and Social Const of IJighway Congestion," Fromemertica, XXIX, 1961, PP, 676-6,99).

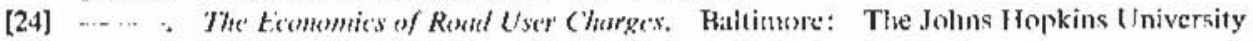
Press, $196 \%$.

[25] Wingo, L. Tramportatiom and Vrinth Land. Washington, 1), (..: Resources for the Future, 1961. 